\title{
DO CONVENTIAL DURATIOS WORK IN PRACTICE?
}

\author{
Bohumil Stádník ${ }^{1}$
}

DOI: https://doi.org/10.31410/ERAZ.S.P.2019.207

\begin{abstract}
The Macaulay Duration could be roughly interpreted as the percentage change of a bond price if the shift of interest rate equals $1 \%$ along the whole zero-coupon curve; which is empirically very rare case. To deal with the prediction of short-term rates shifts and its consequences for the whole yield curve is more often praxis, thus it is useful to define a certain value which respects this fact and which is handled in the same way as Macaulay Duration. We name this measure as "Short Rate Shift Duration" and the main contribution of this study is to suggest a procedure which allows to find its values.
\end{abstract}

Keywords: Short Rate Shift Duration, conventional duration, Macaulay Duration, Short Rate Shift Duration of portfolio, zero-coupon yield curve.

\section{INTRODUCTION}

$\mathrm{P}^{\mathrm{r}}$ rice of an asset with respect to the change of interest rates; and its price sensitivity measurement is a critical issue for an assessment of market risk in case of a portfolio of interest rate sensitive assets, such as bonds or loans.

The value of Macaulay Duration (one of the most popular quantification method for sensitivity issues) could be roughly financially interpreted as the change of a bond price if the shift of interest rate equals $1 \%$ along the whole zero-coupon curve (along the whole spectrum of maturities), when initial price of the bond is equaled to $100 \%$. In this case we may conclude, that the ratio of average price changes of two assets should be approximately the same as the ratio of their Macaulay Durations. But in financial practice this duration is problematic as the parallel curve shift is very rare.

In the financial praxis we deal more often with the prediction of short-term rates shifts and its consequences for the whole yield curve. Movements in short-term interest rates, as dictated by a nation's central bank, will affect different bonds with different terms to maturity differently, depending on the market's expectations of future levels of inflation. For example, a change in short-term interest rates that does not affect long-term interest rates will have little effect on a long-term bond's price and yield. However, a change in short-term interest rates that affect longterm interest rates can greatly affect a long-term bond's price and yield. Put simply, changes in short-term interest rates have more of an effect on short-term bonds than long-term bonds, and changes in long-term interest rates have an effect on long-term bonds, but not on short-term bonds. Thus, it is useful to find a certain value which represents quantification of impact of short rate shifts to bond prices with respect to bond parameters.

The main contribution of this financial engineering study is to suggest a procedure which allows to find a certain measure which can be handled in the same way as conventional Macaulay Duration, for example: in the equation for the change of $\Delta P$, ratio of volatility of two assets, or

Financial Engineering, Department of Banking and Insurance, Faculty of Finance, University of Economics in Prague, W. Churchill sq.4, 14000 Prague, Czech Republic 
in the equation for the duration of portfolio. We also calculate its values for USD interest rate markets. We name this measure as "Short Rate Shift Duration".

This study belongs to a strand in the financial literature focused on basic bonds behaviour such as [1] - [5], bonds volatility [6] - [7], volatility of bonds' determinants [8], bond market price development over medium-run and long-run periods [9] - [13]; or behaviour of a bond portfolio [14].

There are many potential areas for application of our approach. One example being one certain bond life during which its term to maturity is decreasing and the price volatility is changing. One can ask a following question to be answered: How does the volatility development style depend on the time to maturity, coupon rate and on the level of interest rate (yield to maturity)? Because of similarities, another application is a straightforward extension, that being a portfolio of bonds with different maturities at a certain point of time.

Serious research in the area of volatility is provided in [15] - [17] for a practical portfolio management. This text introduced a definition of three different regimes of common bond clean price volatility and examines theoretical and practical repercussions of such phenomena as an extension to the existing literature. A way of determining values of switching points between these regimes with respect to the level of interest rates using numerical calculations are presented and explained. The text includes numerical solving for switching points for maturities from 1 up to 1200 years that show that the switching point 1 (between regime of the "typical" development and other regimes) is of lower value for higher maturities, which is also in accordance with [8]. We can also state that for higher maturities the "switching" point has its practical value within the meaning of today's very low levels or even negative interest rates. The switching point 2 (starting point of "inverse" volatility development) is not of value less than $50 \%$. This value is given by switching point 1 between the lowest maturities for each coupon. If the clean price of a bond is developing inside the volatility envelopes, its sensitivity (volatility) increases/ decreases according to the shown shape of the envelope.

For connected research see also [18] - [25].

\section{METHODOLOGY}

Methodology could be divided into following steps:

1. We take USD empirical zero-coupon curve rates on daily basis (figurel).

2. Based on the empirical data we calculate the daily change of price of fixed coupon bonds with maturities 1 to 30 years (equation $2 b$ ). The coupon is, for the demonstration, set to be $3 \%$ p.a. To keep the same maturity of the bond while we moving day-by-day along the time axis we consider concept of CMT (Constant Maturity Time) bonds.

3. Based on the daily price changes we calculate adequate daily Short Rate Shift Duration in the same way as the Macaulay Duration is calculated (equation 8).

4. We define and calculate Short Rate Shift Duration as mean of daily Short Rate Shift Durations.

5. We calculate the values of Short Rate Shift Duration for different coupons. 


\subsection{Basic Theory}

$$
P(Y T M)=\left(1+Y T M \frac{l}{T}\right)^{-1}\left[c+\frac{c}{(1+Y T M)}+\frac{c}{(1+Y T M)^{2}}+\cdots+\frac{c+100}{(1+Y T M)^{n-1}}\right]
$$

where $P(Y T M)$ is the dirty price of a bond determined in the percentage of its face value on purchasing day, $c$ is the coupon rate per the coupon period, YTM is the yield to maturity per the coupon period, $l$ is the number of days to the next coupon payment, $n$ is the number of coupon payments till the maturity and $T$ is the number of days inside the coupon period.

In the special case when we purchase a bond on the day with zero accrued interest (could be for example an ex-coupon day) and the clean price equals to the dirty price we can use the formula (2a) for the approximation of the required clean price development.

$$
P(Y T M)=\frac{c}{(1+Y T M)}+\frac{c}{(1+Y T M)^{2}}+\cdots+\frac{c+100}{(1+Y T M)^{n}}
$$

We may consider the total price also to be the sum of total prices of $\mathrm{n}$ zero-coupon bonds

$$
P\left(i_{1}, i_{2}, \cdots i_{m a t}\right)=\frac{c}{\left(1+i_{1}\right)}+\frac{c}{\left(1+i_{2}\right)^{2}}+\cdots+\frac{c+100}{\left(1+i_{m a t}\right)^{n}}
$$

where $i_{1}, i_{2}, \ldots i_{\text {mat }}$ are zero-coupon rates for maturities $1,2, \ldots$ years and all other variables have the same interpretation as in equation (1).

Based on the Taylor's theorem for a real-valued function differentiable at the point, there is a polynomial approximation of a higher degree (quadratic, cubic, quartic...) at the fixed-point. Taylor's theorem provides this approximation in a sufficiently small neighbourhood () of the fixed-point $a$ :

$$
f(a+h)=f(a)+f^{\prime}(a) h+\frac{f^{\prime \prime}(a) h^{2}}{2 !}+\frac{f^{\prime \prime \prime}(a) h^{3}}{3 !}+\cdots+R
$$

where formula (3) is applied to formula (2a) and with the substitution: $h$ for $\Delta i$ and $f(a)$ for $P$. Consequently, it can be shown that, the expression (4) holds:

$$
\Delta P(Y T M)=P^{\prime}(Y T M) \Delta Y T M+\frac{P^{\prime \prime}(Y T M) \Delta Y T M^{2}}{2 !}+\frac{P^{\prime \prime \prime}(Y T M) \Delta Y T M^{3}}{3 !}+\cdots+R
$$

where is the remainder of the series and is the change in the market interest rate.

Using the formula (4) for $\Delta P$ (as percentage of its face value) as the general measure of volatility and only up to the second order approximation:

$$
\Delta P(Y T M) \cong-D U R_{M A C} \frac{P(Y T M)}{(1+Y T M)} \Delta Y T M+\frac{1}{2} P(Y T M) C O N V \Delta Y T M^{2}
$$

where $D U R_{M A C}$ is the Macaulay Duration and the term CONV stands for the convexity of the bond. Macaulay Duration can be specified using the following shorthand notation:

$$
D U R_{M A C}=\frac{\sum_{k=1}^{n}\left[\frac{k c}{(1+Y T M)^{k}}\right]+\frac{100 n}{(1+Y T M)^{n}}}{P}
$$




\subsection{Short Rate Shift Duration on Daily Basis}

Using empirical data (figure1) we may calculate Short Rate Shift Duration on daily basis using the first term of the right side of the equation (5)

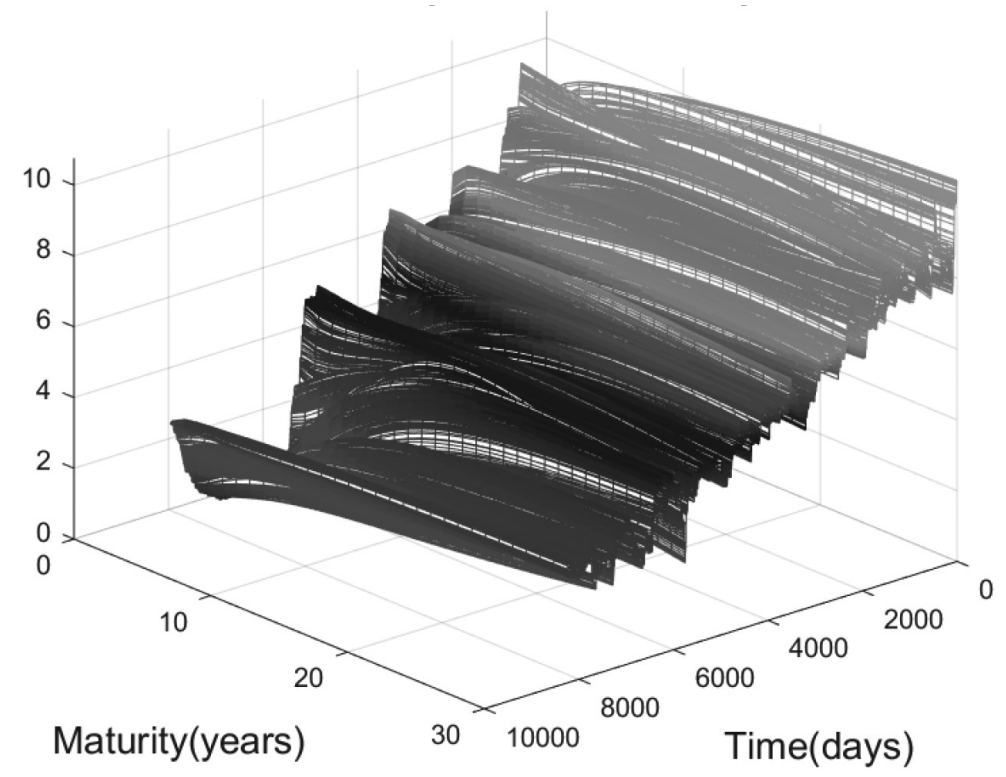

Figure 1: USD zero coupon yield curve development

$$
D U R_{S R S_{d}}(m a t, d, Y T M) \cong-\frac{Y T M}{P_{m a t, d}} \frac{\Delta P_{m a t, d}}{\Delta Y T M}
$$

where
$D U R_{S R S_{-} d}($ mat, $d, Y T M)$
Short Rate Shift Duration on daily basis as function of maturi-
ty, day, yield to maturity (Figure 1)
YTM
$\triangle \mathrm{YTM}$
$P_{(m a t, d,)}$ yield to maturity
$\Delta \mathrm{P}_{(m a t, d,)}$ change of YTM of the short term rate (1 year) price of bond with respect to its time to maturity and the struc- ture of zero coupon curve on day $d$ change of price between $d$ and $d-1$ (according to Figure 1) number of days (from the beginning of time series, Figure1 )

\subsection{Short Rate Shift Duration Definition}

Let's define Short Rate Shift Duration like mean value with respect of $d$

$$
D U R_{S R S}=E\left[D U R_{S R S_{-} d}(\operatorname{mat}, d, Y T M)\right]
$$

\subsection{Short Rate Shift Duration of Portfolio}

With Short Rate Shift Duration we may deal in the same way as with Macaulay Duration and express Short Rate Shift Duration of portfolio:

$$
D U R_{S R S \_P O R T F}=\sum_{j=1}^{n} w_{j} D U R_{S R S j}
$$

Where $w_{\mathrm{j}}$ is the weight of $\mathrm{jth}$ asset in the portfolio. 


\section{RESULTS}

We may observe many cases, by the way of example in the figure2, of inverse shifts along zero-coupon yield curve which could decrease the change of price in case of typical coupon bond in comparison to our estimation using Macaulay Duration, which use the same shift along the whole curve.

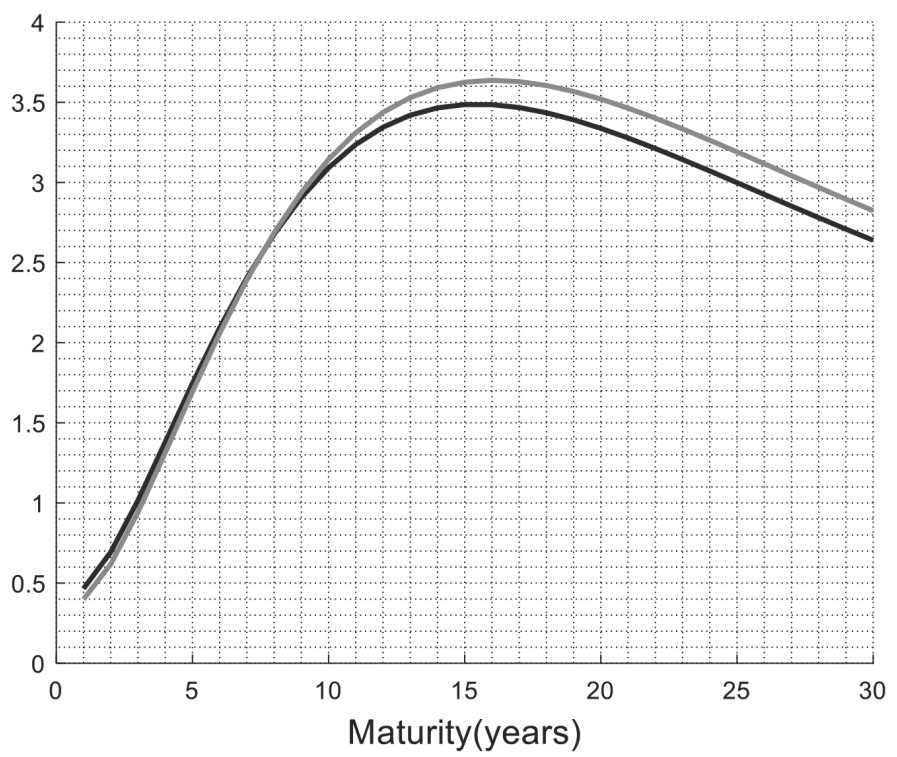

Figure 2: Inverse interest rate shift example

Day to day price shifts (30- and 1-year maturities) according to figure 1 we may observe in the figure 3.

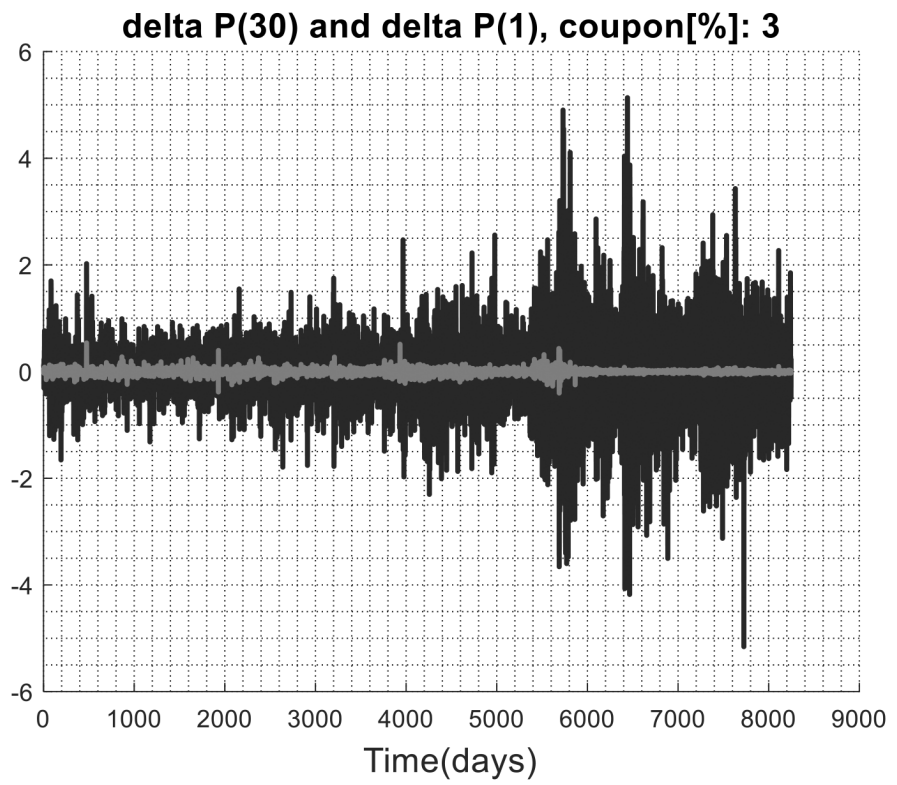

Figure 3: 30 and 1 maturities bond price shifts

The average ratio of day to day price change is in the figure 4. According to Macaulay Duration, the ratio of price changes should be approximately equaled to the ratio of Macaulay Durations. From the figure is clear that beginning maturity higher than 5such idea does not work. 


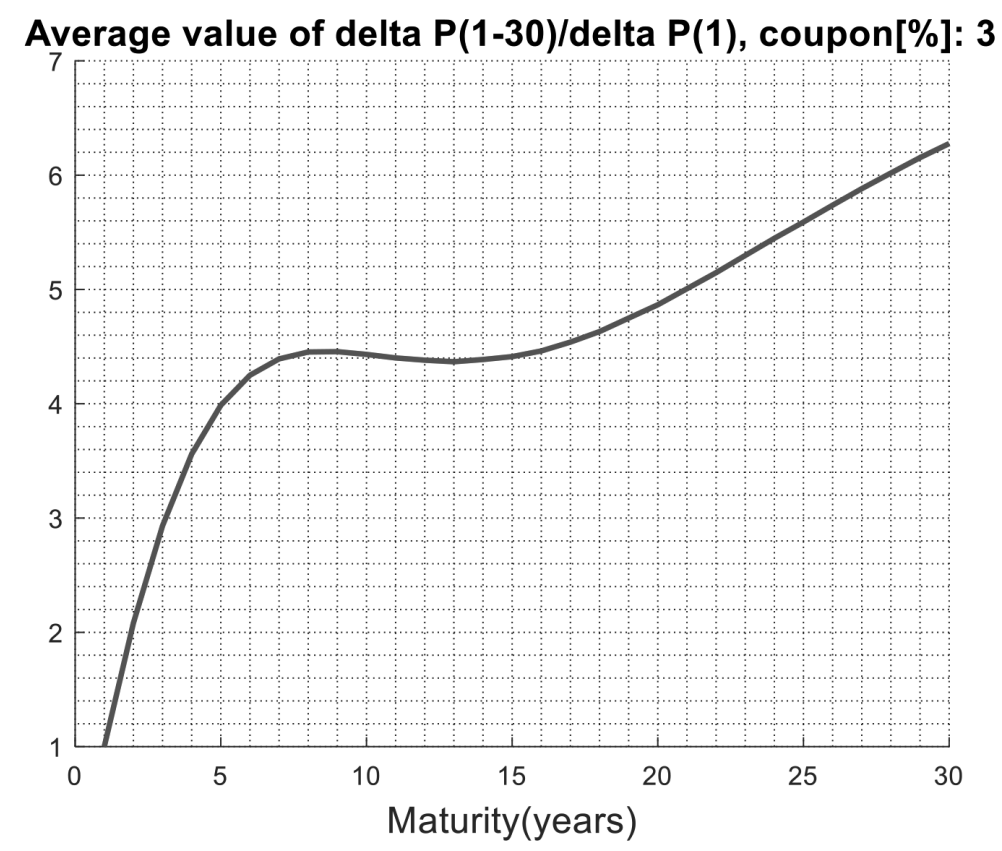

Figure 4: Average value of ratio of prices shifts

Ratio of inverse price shifts over all the shifts is in the figure 5. From the figure it is clear that approximately in $30 \%$ cases the change of price of long fixed coupon bond (longer than 10 years) goes in the opposite direction than the price movement of on year bond.

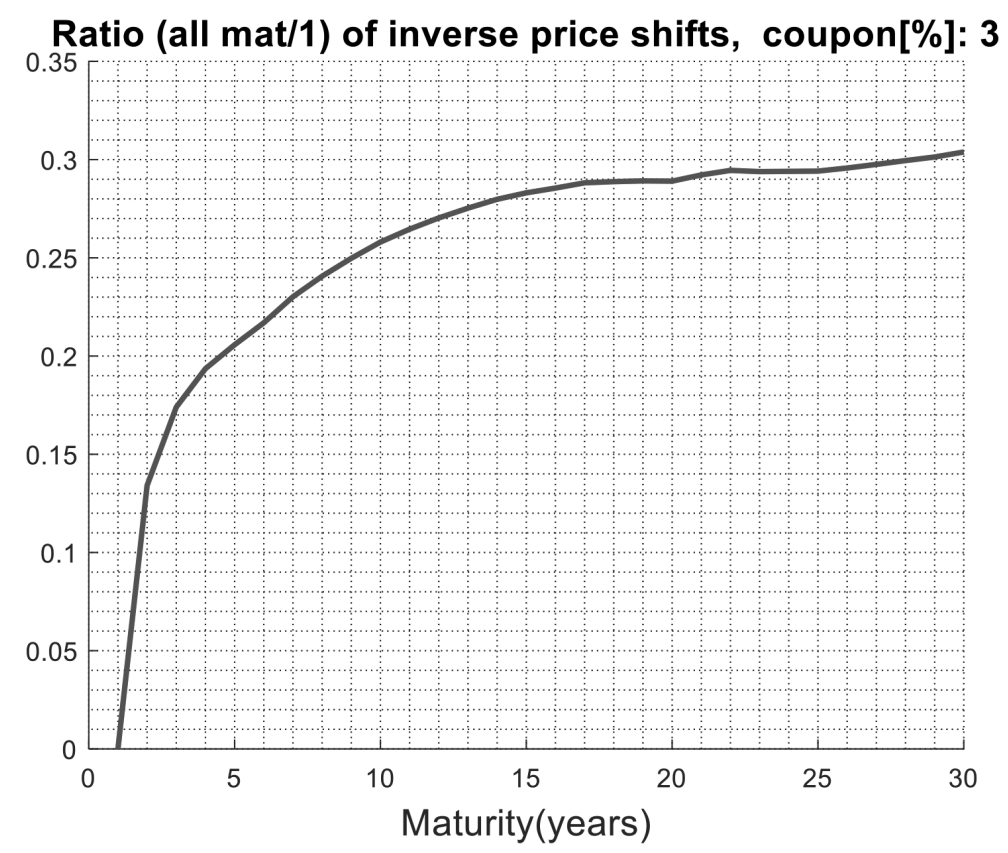

Figure 5: Ratio of inverse price shifts

This is also the reason of the degressive shape of the curve in the figure 4. In the figure 6 there is ratio of change of price for different maturities. Values of Short Rate Shift Duration in comparison to Macaulay Duration is in the figure 7.

Dependence of Short Rate Shift Duration on coupon rate and maturity is in the figure 8. With higher coupon the value is lower. The same feature we observe in case of Macaulay Duration. Exact values are in the table 1. 
Average value of delta $P(A) /$ delta $P(B)$, coupon[\%]: 3

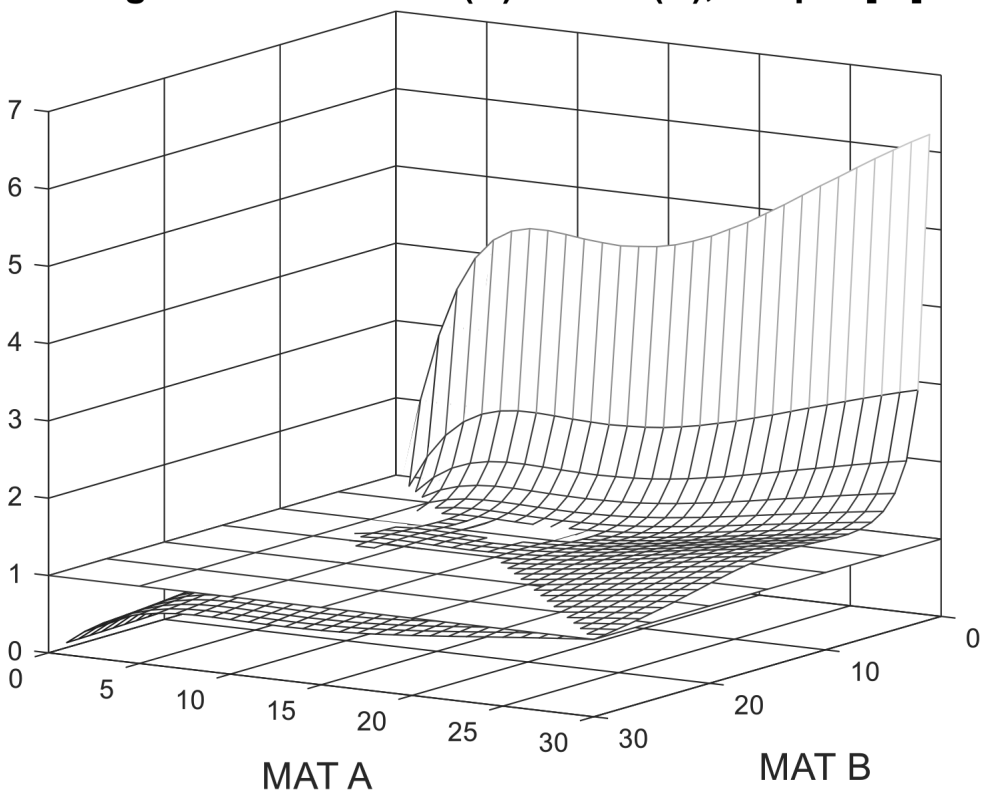

Figure 6: Ratio of inverse price shifts

Short Rate Shift Dur.(thick line) and Macaulay's duration, coupon[\%]: 3

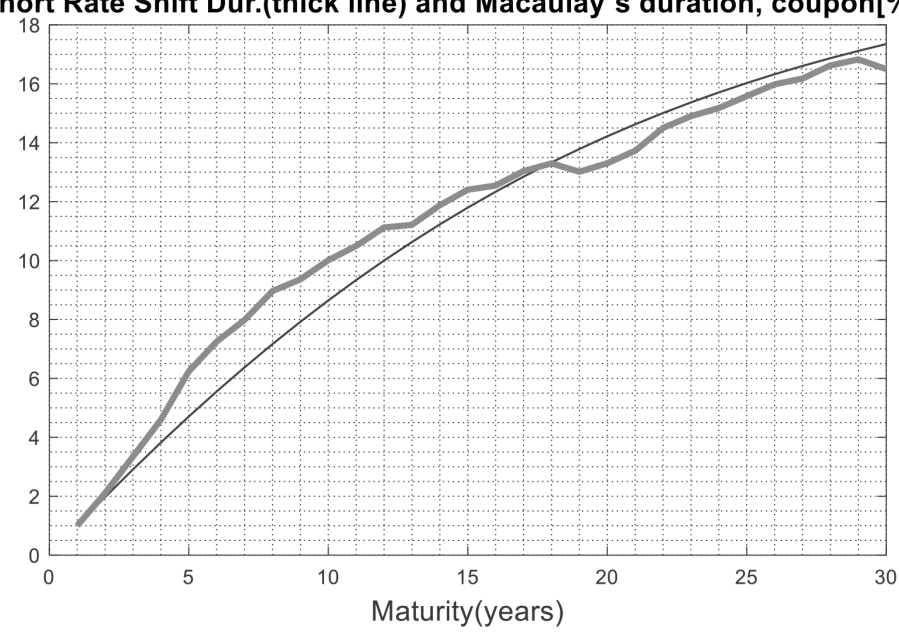

Figure 7: Empirical and Macaulay Duration (coupon=3)

Table 1: Short Rate Shift Duration, USD

\begin{tabular}{|r|r|r|r|r|r|r|r|}
\hline MAT\COUPON & 1 & 2 & 3 & 4 & 5 & 6 & 7 \\
\hline 1 & 1 & 1 & 1 & 1 & 1 & 1 & 1 \\
\hline 2 & 1,99 & 1,98 & 1,97 & 1,96 & 1,95 & 1,94 & 1,94 \\
\hline 3 & 2,97 & 2,94 & 2,91 & 2,89 & 2,86 & 2,84 & 2,82 \\
\hline 4 & 3,94 & 3,88 & 3,82 & 3,77 & 3,73 & 3,68 & 3,64 \\
\hline 5 & 4,89 & 4,79 & 4,71 & 4,63 & 4,55 & 4,49 & 4,42 \\
\hline 6 & 5,83 & 5,69 & 5,56 & 5,44 & 5,34 & 5,24 & 5,16 \\
\hline 7 & 6,76 & 6,56 & 6,38 & 6,22 & 6,08 & 5,96 & 5,85 \\
\hline 8 & 7,67 & 7,4 & 7,17 & 6,97 & 6,79 & 6,64 & 6,51 \\
\hline 9 & 8,57 & 8,22 & 7,92 & 7,68 & 7,47 & 7,28 & 7,12 \\
\hline 10 & 9,45 & 9,01 & 8,65 & 8,35 & 8,1 & 7,89 & 7,7 \\
\hline 11 & 10,3 & 9,77 & 9,34 & 8,99 & 8,7 & 8,46 & 8,25 \\
\hline 12 & 11,14 & 10,5 & 10 & 9,6 & 9,28 & 9 & 9,77 \\
\hline 13 & 11,96 & 11,2 & 10,63 & 10,18 & 9,81 & 9,52 & 9,26 \\
\hline 14 & 12,75 & 11,88 & 11,23 & 10,72 & 10,32 & 10 & 9,73 \\
\hline
\end{tabular}




\begin{tabular}{|r|r|r|r|r|r|r|r|}
\hline MAT\COUPON & 1 & 2 & 3 & 4 & 5 & 6 & 7 \\
\hline 15 & 13,52 & 12,52 & 11,79 & 11,24 & 10,81 & 10,46 & 10,17 \\
\hline 16 & 14,27 & 13,13 & 12,33 & 11,73 & 11,26 & 10,89 & 10,59 \\
\hline 17 & 14,99 & 13,72 & 12,84 & 12,19 & 11,7 & 11,3 & 10,98 \\
\hline 18 & 15,69 & 14,28 & 13,32 & 12,63 & 12,1 & 11,69 & 11,36 \\
\hline 19 & 16,36 & 14,81 & 13,78 & 13,04 & 12,49 & 12,06 & 11,72 \\
\hline 20 & 17,01 & 15,31 & 14,21 & 13,43 & 12,86 & 12,41 & 12,06 \\
\hline 21 & 17,62 & 15,78 & 14,61 & 13,8 & 13,2 & 12,75 & 12,38 \\
\hline 22 & 18,22 & 16,23 & 15 & 14,15 & 13,53 & 13,06 & 12,69 \\
\hline 23 & 18,78 & 16,66 & 15,36 & 14,48 & 13,85 & 13,37 & 12,99 \\
\hline 24 & 19,32 & 17,05 & 15,7 & 14,79 & 14,14 & 13,65 & 13,27 \\
\hline 25 & 19,84 & 17,43 & 16,02 & 15,09 & 14,43 & 13,93 & 13,54 \\
\hline 26 & 20,32 & 17,79 & 16,33 & 15,37 & 14,7 & 14,19 & 13,8 \\
\hline 27 & 20,79 & 18,12 & 16,61 & 15,64 & 14,95 & 14,45 & 14,05 \\
\hline 28 & 21,22 & 18,43 & 16,88 & 15,89 & 15,2 & 14,69 & 14,29 \\
\hline 29 & 21,64 & 18,73 & 17,14 & 16,13 & 15,43 & 14,92 & 14,52 \\
\hline 30 & 22,03 & 19,01 & 17,38 & 16,36 & 15,65 & 15,14 & 14,75 \\
\hline
\end{tabular}

Short Rate Shift Dur./coupon/maturity, USD

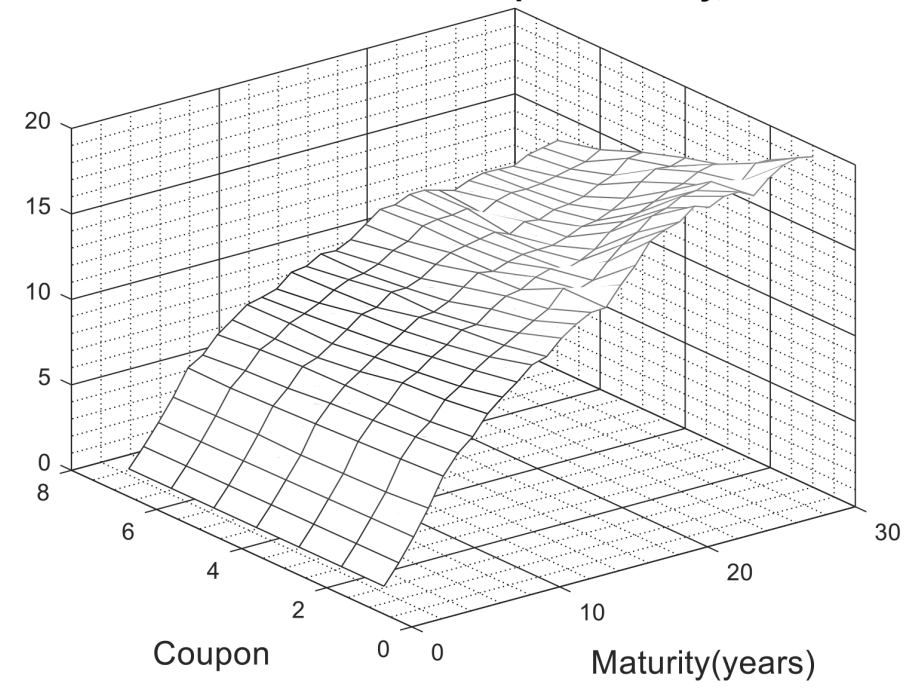

Figure 8: Short Rate Shift Duration/coupon/maturity

The comparison of zero coupon-bond Short Rate Shift Duration and of Macaulay Duration, which is straight line, is in the figure 9.

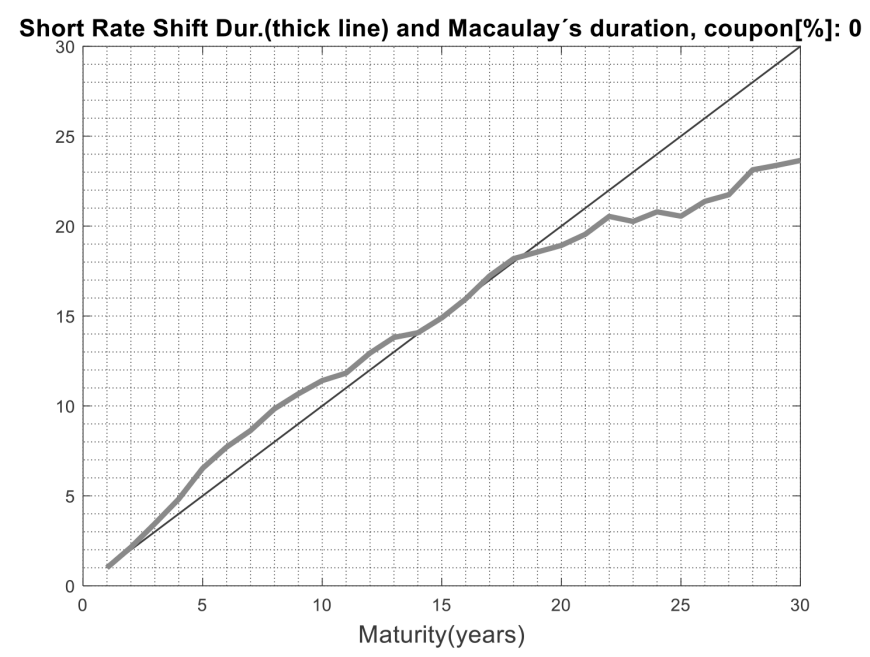

Figure 9: Zero coupon-bond Short Rate Shift Duration and its Macaulay Duration 


\section{CONCLUSION}

We may conclude that the question formulated in the title has negative answer. Typical one, among conventional durations, is Macaulay Duration. Its main problem is, that it assumes the parallel zero-coupon curve shifts along the whole curve which is not realistic presumption.

In this research we have defined and also quantified (for USD zero-coupon rates) a new duration - Short Rate Shift Duration which is based on the empirical development of zero-coupon curve. Short Rate Shift Duration is a certain measure which can be handled in the same way as conventional Macaulay Duration, by the way of example: in the equation for the change of $\Delta \mathrm{P}$, ratio of volatilities of two bonds, or in the equation for duration of a portfolio.

As the curve movements are in approximately in $30 \%$ of all the cases inverse, we expect the price volatility of fixed coupon bonds with long maturities to be lower than it should be according Macaulay Duration. Values of Short Rate Shift Duration, which is basically quantification of such effect, have supported these expectations. The value of Short Rate Shift Duration also decreases with higher coupon and increases with longer term to maturity as in the case of Macaulay Duration.

Based on the reasons above we may conclude that long bonds (over 20 years to maturity) are not as risky as it is considered to be based on Macaulay Duration, in comparison to the short bonds. On the other hand, based on figure 9 or 7 it is possible to conclude that bonds within the maturity up to 15 years are more sensitive to the change of short rate in comparison to Macaulay Duration concept.

The values of Short Rate Shift Duration are based on empirical data of zero-coupon rates for certain currency.

\section{ACKNOWLEDGEMENT}

The research has been supported by institutional grant VŠE IP 100040 , VŠE IG102027 and GAČR 18-05244S.

\section{REFERENCES}

[1] Fabozzi, F., J. 1993. Fixed Income Mathematics, Chicago: Probus, Publishing Company.

[2] Fabozzi, F. J., Fabozzi, T., D.1995. The Handbook of Fixed Income Securities (Fourth Edition). Irwin, Professional Publishing, 1995.

[3] Fabozzi F., J. 2010. Bond Markets, Analysis and Strategies (seventh edition). Prentice Hall.

[4] Smit, L. A., Swart, B. B. 2006. Calculating the price of bond convexity. Journal of Portfolio Management, Volume 32, Issue 2, pp. 99-106.

[5] Málek, J., Radová, J., Štěrba, F. 2007. Yield curve construction using government bonds in the Czech Republic. Politická ekonomie, vol. LV, 2007, iss. 6, pp. 792-808.

[6] Litterman, R., Scheinkman, J. 1991. Common factors affecting bond returns. The Journal of Fixed Income, vol. 1, June 1991, no. 1, pp. 54-61.

[7] Litterman, R., Scheinkman, J., Weiss, L. 1991. Volatility and the yield curve. The Journal of Fixed Income, vol. 1, June 1991, no. 1, pp. 49-53.

[8] Fuller, R. J., Settle, J. W. 1984. Determinants of Duration and Bond Volatility. Journal of Portfolio Management, Vol. 10, No. 4, pp. 66-72. 
[9] Chance, D. M., Jordan, J. V. 1966. Duration, convexity, and time as components of bond returns. The Journal of Fixed Income, vol. 6, September 1966, no. 2, pp. 88-96.

[10] Kang, J. C., Chen, A. H. 2002. Evidence on theta and convexity in treasury returns. The Journal of Fixed Income, vol. 12, June 2002, no. 1, pp. 41-50.

[11] Tvaronavičienea, M., Michailova, J. 2006. Factors affecting securities prices: Theoretical versus practical approach. Journal of Business Economics and Management, Volume 7, Issue 4, pp. 213-222.

[12] Křepelova, M., Jablonský, J. 2013. Analýza státních dluhopisů jako indikátoru pro akciový trh. Politická ekonomie, vol. LXI, no. 5, pp. 605-622.

[13] Visokavičienè, B. 2008. Money Supply and Assets Value. Business: Theory and Practice/ Verslas: Teorija ir Praktika, Volume 9, No 3, pp. 210-214.

[14] Dzikevičius, A., Vetrov, V. 2013. Investment Portfolio Management Using the Business Cycle Approach. Business: Theory and Practice/Verslas: Teorija ir Praktika, Vol 14, No 1, pp. 57-63.

[15] Stádník, B. 2012. Theory and Praxis of Bonds I. Oeconomica, University of Economics, Prague.

[16] Stádník, B. 2014. The Volatility Puzzle of bonds. 8th International Scientific Conference: Business and Management 2014, May 15-16, 2014, Vilnius.

[17] Stádník, B., Žd'árek, V.2017.Volatility 'Strangeness' of Bonds - How to Define and What Does it Bring? Prague Economic Papers Vol. 26 No. 5

[18] Steeley, J. M. 2006. Volatility transmission between stock and bond markets, Journal of International Financial Markets, Institutions and Money, Volume 16, Issue 1:71-86, Aston Business School, Aston University, Birmingham B4 7ET, United Kingdom.

[19] Janda, K., Rausser, G., Svárovská, B. 2014. Can Investment in Microfinance Funds Improve Risk-Return Characteristics of a Portfolio? Technological and Economic Development of Economy, 2014, Volume 20, Issue 4, pp. 673-695.

[20] Janda, K., Svárovská, B. 2010. Investing into microfinance. Journal of Business Economics and Management, Volume 11, Issue 3, pp. 483-510.

[21] Ortobelli, S., Tichý, T. 2015. On the impact of semidefinite positive correlation measures in portfolio theory. Annals of Operations Research 235: 625-652, 2015. ISSN 0254-5330. 10.1007/s10479-015-1962-x.

[22] Giacometti, R., Ortobelli, S., Tichý, T. 2015. Portfolio selection with uncertainty measures consistent with additive shifts. Prague Economic Papers 24 (1): 3-16, 2015. ISSN 12100455

[23] Blahová, N. 2015. Analysis of the Relation between Macroprudential and Microprudential Policy. European Financial and Accounting Journal, vol. 10, 2015, no. 1, pp. 33-47.

[24] Brůna, K., Blahová, N. 2016. Systemic Liquidity Shocks and Banking Sector Liquidity Characteristics on the Eve of Liquidity Coverage Ratio Application - The Case of the Czech Republic. Journal of Central Banking Theory and Practice [online], vol. 5, 2016, no. 1, pp. 159-184. DOI: $10.1515 /$ jcbtp-2016-0008.

[25] Webb, M. S. 2015. Negative yields are all around us. The Financial Times, FTMoney, Saturday 31 January 2015, p. 8. 